\title{
ESTADÍSTICA Y HACIENDA EN UNA SOCIEDAD DE PATRONAZGO: LA ESPAÑA RURAL DEL SIGLO XIX*
}

\author{
Juan Pro Ruiz**
}

\section{Un Estado en construcción}

El fenómeno histórico que domina el siglo XIX en España -como en toda Europa occidental- es la construcción del Estado: el Estado propiamente dicho, es decir, el Estado-nación contemporáneo de inspiración liberal. La Monarquía española se hundió a partir de 1808 y dejó un vacío de poder que se fue colmando con la lenta construcción del Estado. Este proceso no se completó plenamente hasta finales del siglo XIX, cuando la presencia de la burocracia estatal empezó a hacerse efectiva en todo el territorio nacional.

La construcción del Estado implica el desarrollo de una burocracia moderna. Es, por lo tanto un proceso de acumulación de recursos materiales e inmateriales en manos de un poder político central que controla a dicha burocracia. Entre los recursos materiales que se acumularon durante el proceso de construcción del Estado destacan por su importancia los que sirvieron para cubrir las crecientes necesidades financieras de la burocracia estatal. Para responder a esa necesidad se construyó un sistema regular de ingresos, al cual se conoce como Hacienda Pública.

En cuanto a los recursos inmateriales, cabe destacar entre ellos un tipo especialmente relevante: los instrumentos destinados a cubrir las necesidades informativas acerca del territorio, la población y los recursos económicos. Para conocer su distribución y evolución se construyó un sistema estadístico público al servicio del gobierno, que -como no se cansan de repetir los textos de la

* Este artículo ha sido elaborado en el marco del proyecto de investigación PB97-0056, financiado por la Dirección General de Investigación Científica y Técnica.

** Universidad Autónoma de Madrid. 
época- era esencial para orientar la acción política, para saber qué país se estaba gobernando, detectar los recursos, recaudar los impuestos y cubrir así las necesidades materiales.

Estos dos aspectos son cruciales en la construcción del Estado: la Hacienda y la estadística fueron -y son- dos pilares fundamentales del Estado contemporáneo. Sin ellos el Estado no podría desempeñar su papel de modernizador de la economía y de la sociedad: no podría regular la economía, ni impulsar el desarrollo económico; y, por paradójico que resulte, si el Estado no regula la economía es imposible el funcionamiento de una economía de mercado. Sin ellos no podría tampoco el Estado realizar la labor de "ingeniería social" necesaria para el nacimiento y consolidación de una sociedad de clases, aboliendo las viejas formas de privilegio y desigualdad, y creando nuevas discriminaciones y formas modernas de distinción.

Vamos a ver cómo y por qué los constructores del Estado de la España del siglo XIX hallaron tantas dificultades para proporcionar a aquel Estado naciente una base financiera y estadística sólida; asunto importante, ya que de ese retraso en el cierre de la administración estadística y fiscal resultaría un retraso en la propia construcción del Estado, que no concluiría hasta un siglo más tarde (ya en el siglo XX); y, en consecuencia, la situación de atraso y estancamiento económico y social que arrastraba el país se prolongó cien años más de lo que los liberales de los primeros momentos habían planeado.

El sistema tributario no fue reformado por los liberales hasta 1845; e incluso en ese momento, la de Mon fue una reforma continuista, concebida y aplicada con criterios conservadores, que creó un sistema tributario injusto, regresivo, insuficiente y poco flexible. Un sistema tributario incapaz de hacer que sus rendimientos crecieran al ritmo que lo hacía la economía. Fue, por lo tanto, un sistema que abocó a un déficit presupuestario estructural hasta la reforma tributaria de Fernando de Villaverde de 1899-1900, que inició un período de estabilidad'.

En cuanto al sistema estadístico, no empezó a construirse hasta 1857, con la elaboración del primer censo; y estuvo lastrado por frecuentes cambios de criterio en la orientación de los trabajos estadísticos y, sobre todo, por insuficiencias de personal y de presupuesto que obligaban al gobierno a depender de informaciones no contrastadas suministradas por terceros (principalmente los ayuntamientos). En consecuencia, el sistema estadístico español de la segunda mitad del XIX arroja, en general, datos poco fiables. Hasta finales del siglo XIX los datos estadísticos de los que se disponía en España eran extraordinariamente poco fiables².

1. Un reciente balance del resultado de ambas reformas puede encontrarse en las monografías colectivas de Hacienda Pública Española impulsadas por Francisco Comín: "La reforma fiscal de Mon-Santillán ciento cincuenta años después" (Madrid, 1996) y "Villaverde en Hacienda, cien años después" (Madrid, 1999).

2. Juan Pan-Montojo: “Fuentes estadísticas", en M. Artola (dir.): Enciclopedia de Historia de España. VII. Fuentes. Índice, Alianza Editorial, Madrid, 1993, pp. 369-421. 
Estos dos sistemas, el tributario y el estadístico, estaban muy relacionados entre sí. El sistema tributario no podía modernizarse si le faltaban los instrumentos estadísticos para conocer la distribución de la propiedad, de la riqueza y de la renta, situación que le impedía recaudar eficazmente. El sistema estadístico, por su parte, encontraba obstáculos para su modernización porque existía el temor a que aumentase el control estatal sobre la sociedad y la economía. Se temía, en particular, a las consecuencias fiscales que pudiera tener una mayor intromisión de la administración central en la realidad económica de los pueblos y ciudades. Este temor hizo que se boicotearan muchos intentos de obtener datos fiables. La pieza que relacionaba ambos sistemas, el sistema tributario y el estadístico, era el catastro.

\section{Primeras frustraciones y primeros enfrentamientos en busca de un catastro}

El modelo del catastro español quedó fijado en el siglo XVIII por los catastros de Patiño -en Cataluña, desde 1715- y de Ensenada -en la Corona de Castilla, desde 1749-: eran catastros literales, meras listas escritas de propiedades y propietarios, con una estimación de la superficie y del valor de las parcelas, pero sin el apoyo de planos. La información necesaria para construir esas listas procedía de las declaraciones de los propios interesados, revisadas y complementadas únicamente por comisiones locales de constitución claramente oligárquica: comisiones en las que se daba cabida a los mayores propietarios y a las familias más poderosas de cada pueblo. Resulta obvio que un mecanismo de obtención de información como este permite una evasión masiva, una ocultación sistemática de la riqueza. No había planos objetivos que permitieran localizar las ocultaciones, denunciarlas ni contrarrestarlas. No hubo, en todo aquel proceso, agentes independientes que pudiesen comprobar y corregir las informaciones interesadas que daban los poderosos o los principales contribuyentes. La facilidad para canalizar la ocultación fiscal de la riqueza fue la principal razón por la que este modelo de catastro literal se consolidó como la fórmula tradicional, ya que contaba con las preferencias de los grandes terratenientes.

Cuando en el siglo XVIII se planteó la realización de un catastro, dos fueron las opciones barajadas para su elaboración: un catastro gráfico o un catastro literal. El catastro gráfico es el verdadero catastro, el que incluye planos de las fincas y de los términos municipales. Estos planos sirven para comprobar la superficie de las parcelas, característica esencial para poder evaluar las propiedades territoriales, conocer a ciencia cierta su extensión, completar el rompecabezas del parcelario y, de esta manera, controlar que no haya fincas que hayan escapado del impuesto. Este apoyo en planos es lo que hace eficaz al catastro gráfico. El problema era que levantar planos exigía recursos técnicos, humanos y económicos muy abundantes; recursos que los Estados del siglo XVIII no poseían, y desde luego no la Monarquía española. Faltaban los geómetras y el personal técnico y administrativo al servicio de la Monar- 
quía que hubieran permitido no depender de las informaciones verbales dadas por los interesados.

En consecuencia, se optó por el catastro literal, descrito más arriba: esa lista verbal de propiedades sin planos a escala ni mediciones rigurosas, que era una alternativa barata, rápida, factible... y que mantenía a salvo los intereses de los grandes terratenientes, lo cual hacía que su realización levantara menos resistencias. Si tenemos en cuenta que los grandes propietarios de la tierra, en términos generales, pueden considerarse como el grupo social que ha controlado el poder político en España a lo largo de todo el siglo XIX y gran parte del $X X$, no resulta extraño que esta opción se consolidara, aun cuando técnicamente había quedado desfasada ya en Europa: España sería el único país europeo que mantendría este modelo a finales del siglo XIX.

Por las razones apuntadas, el catastro literal -que no es un auténtico catastro- ha sido la tradición histórica de este país en materia de impuestos aproximadamente hasta mediados del siglo XX. Todos los intentos de sustituirlo por un catastro gráfico moderno han encontrado grandes dificultades políticas para salir adelante.

Paradójicamente, el catastro literal se convirtió en la máxima aspiración reformista de los diferentes gobiernos, ya que ni siquiera se consiguió mantener este tipo de catastros tan burdos. El catastro de Ensenada no llegó a tener continuidad, su aplicación fiscal se limitó a un momento muy concreto y se tardó mucho tiempo en volver a tener algo parecido ${ }^{3}$.

\section{Renuncias y privilegios en el Estado liberal}

La tradición de los catastros literales continuó en el siglo XIX. Cuando se puso en marcha la reforma tributaria de 1845, hacía falta dotar a la Hacienda de la documentación básica para el reparto de los nuevos impuestos que se habían definido. Esto hizo aparecer nuevamente el debate del catastro. Un doble debate, en realidad: si debía emprenderse el levantamiento de un catastro o no; y, en caso positivo, qué tipo de catastro. La reforma creó un sistema de impuestos reales o de producto, basados en el principio liberal de la igualdad; principio que, en aquella época, se entendía en un sentido de proporcio-

3. Una descripción detallada delos procedimientos del Catastro de Ensenada y de los documentos resultantes, en: Concepción Camarero Bullón: Burgos y el Catastro de Ensenada, Caja de Ahorros Municipal, Burgos, 1989. Los problemas surgidos para su implantación los ha estudiado Alfonso Otazu: La reforma fiscal en la España moderna: el caso de Extremadura, Instituto de Estudios Fiscales, Madrid, 1979. Una presentación del catastro catalán de 1715, en: Antoni Segura i Mas: "El catastro de Patiño en Cataluña" (en: A. Segura, coord.: El catastro en España, I: 1714-1906. De los catastros del siglo XVIII a los amillaramientos de la segunda mitad del siglo XIX, Centro de Gestión Catastral y Cooperación Tributaria / Editorial Lunwerg, Madrid, 1988, pp. 31-44); en el mismo volumen se encuentra también una contextualización política de los proyectos tributarios del momento en la Corona de Aragón. 
nalidad (que las cuotas de cada contribuyente fueran proporcionales a la renta que percibían). La reforma creaba un impuesto para cada forma de renta; y, como se trataba de un país esencialmente agrario, de esa batería de impuestos que se destinaban a gravar cada una de las clases de renta, el impuesto más importante, en un primer momento, fue la Contribución de Inmuebles, Cultivo y Ganadería o Contribución Territorial, es decir, el impuesto orientado específicamente a las actividades agropecuarias. Para recaudarlo era imprescindible un registro en el que constara el reparto exacto de la propiedad, requisito para garantizar la buscada equidad.

El objetivo teórico de la equidad, es decir, de la proporcionalidad en el reparto del impuesto, chocaba con la realidad de que los grandes propietarios de tierras eran los que dominaban la sociedad rural y los poderes municipales; y con el hecho de que su colaboración fuera indispensable, no sólo para recaudar y repartir el impuesto, sino también para asentar el Estado liberal ganando la guerra civil contra los carlistas, en un primer momento, y para consolidar el nuevo Estado a partir de 1840. Se estableció así una colaboración entre el poder central y los poderes locales a largo plazo, colaboración de la cual las oligarquías locales debían obtener algún beneficio.

Los terratenientes impusieron la continuidad del modelo tradicional de catastros, el modelo literal que se había ensayado con escaso éxito desde principios del siglo XVIII. Esos catastros literales, que dejaban la puerta abierta al fraude y a la evasión, tenían otra característica muy interesante: eran elaborados por los ayuntamientos, es decir, por instituciones locales controladas por los propios notables del lugar. Esta descentralización era esencial, puesto que hacía a este tipo de catastros muy manipulables desde el poder local, permitiendo desfigurar en la práctica el principio de proporcionalidad del tributo, al instalar prácticas de fraude fiscal masivas y toleradas. El documento en cuestión, el tipo de catastro que se elaboró a partir de 1850 para recaudar la Contribución de Inmuebles, Cultivo y Ganadería, fue el Ilamado amillaramiento, y estuvo funcionando como base para la recaudación de este impuesto desde 1850 hasta una fecha indeterminada (ya que en unos municipios terminó antes y en otros después), pero en cualquier caso y de forma generalizada hasta 1950.

Los amillaramientos dieron lugar a un fraude masivo, que llegó hasta el 85 por 100 de la superficie en algunas provincias, si bien la ocultación media general estimada (a comienzos de la Restauración) estaba en torno al 40 por 100. Estas cifras tan altas de ocultación indican que el problema no estaba en la torpeza del instrumento estadístico empleado. Cientramente, los amillaramientos eran un sistema de información muy impreciso, pero la clave de su incapacidad para censar la riqueza no estaba en esta imprecisión, sino en que sus datos procedían de una negociación política con los poderes locales y no de una investigación directa de la riqueza. 
La negociación, lubricante universal del Estado liberal español, se regía por la lógica del intercambio de favores entre las oligarquías locales, las oligarquías provinciales y la clase política nacional. Esto permitía la ocultación y el fraude en grandes proporciones $y$, sobre todo, permitía un acceso desigual a la ocultación: eran los ricos, los poderosos, los que más impunemente podían ocultar. En consecuencia el reparto de la carga tributaria era extremadamente injusto: quienes menos podían eludirla eran precisamente quienes tenían menos acceso a los poderes públicos y fundamentalmente al poder local, el cual, como es sabido, estaba en manos de los grandes propietarios.

Las minorías progresistas del siglo XIX señalaron insistentemente, al referirse a la necesidad de modernizar el Estado, la Administración pública y el sistema tributario, la necesidad de hacer realidad la idea teórica de la igualdad ante el impuesto, incluyendo el catastro como componente de esa utopía progresista. Defendieron muchas veces que había que implantar en España un catastro gráfico, lo cual no significaba más que homologar a España con el resto de la Europa continental, en la medida en que, a partir del catastro napoleónico de principios del XIX, la idea de un catastro gráfico para el reparto de los impuestos sobre la propiedad y uso de la tierra se fue difundiendo gradualmente por la Europa continental con escasísimas excepciones. A finales del siglo XIX prácticamente la totalidad de países de la Europa continental tenían algún tipo de catastro gráfico, de mejor o peor calidad, con o sin valor jurídico.

El tema del catastro apareció insistentemente en los programas de los progresistas de la segunda mitad del XIX. Hubo multitud de proyectos para realizar un catastro, ya que éste era considerado la llave del progreso del país, llave que iba a permitir que el Estado se financiara, adquiriera fuerza y eficiencia, al tiempo que se que se produjera un reparto menos desigual de la riqueza. Todos estos proyectos fracasaron ante la oposición de los grandes terratenientes que, amparados por las fuerzas políticas conservadoras, hicieron que el sistema de amillaramientos haya pervivido hasta mediados del siglo XX.

La resistencia de los terratenientes y de las oligarquías locales a un catastro fiscal que pudiera amenazar sus intereses hizo que las labores de cartografía catastral -es decir, los trabajos para la realización de un catastro gráfico-, que se inició a mediados del siglo XIX, no corrieran a cargo del Ministerio de Hacienda, sino que quedaron encomendadas a otras instituciones más inofensivas. Instituciones ligadas principalmente a los militares y controladas desde la Presidencia del Gobierno, como fueron la Comisión de Estadística General del Reino, la Junta General de Estadística y, desde 1870 y hasta nuestros días, el Instituto Geográfico ${ }^{4}$. Era una forma de evitar que tuviera consecuencias fiscales

4. La historia de estas instituciones y de sus trabajos se encuentra analizada en: José Ignacio Muro, Francesc Nadal y Luis Urteaga: Geografía, estadística y catastro en España, 18561870, Serbal, Barcelona, 1996. 
ese trabajo de levantamiento de planos rigurosos y fiables en los que se incluyera el parcelario.

Este tipo de instituciones desvinculadas del Ministerio de Hacienda realizaron el deslinde y la medición de los términos municipales, primer paso para poder después conocer mejor el parcelario. Un objetivo tan modesto (políticamente hablando) como el de deslindar los términos municipales requirió ya una batalla muy dura. Una vez trazado el perímetro, con unas nociones elementales de geometría resultaba fácil calcular la superficie de cada término municipal; y una vez calculada la superficie, se podía comparar con la que ese mismo término municipal tenía declarada a efectos fiscales en su amirallamiento. La publicación de las listas en las que se comparaban las superficies medidas objetivamente y las resultantes de sumar lo declarado en los amillaramientos supuso un gran escándalo, ya que se descubrió una dispersión enorme en el grado de error que contenían los amillaramientos vigentes: había pueblos que tenían una superficie declarada mayor que la que de hecho se había medido, otros -pocos- que se ajustaban aproximadamente, y una inmensa mayoría que presentaban grandes ocultaciones, con una media en torno al 40 por 100. La consiguiente indignación de la opinión pública contribuyó a crear un clima de consenso nacional en torno a la necesidad de un catastro gráfico. España no sólo se había quedado rezagada con respecto a cualquier país comparable de la Europa continental, sino que además la situación había sido puesta en evidencia por gente nada sospechosa, como eran los ingenieros militares.

Al mismo tiempo, aquellos trabajos del Instituto Geográfico y de las instituciones que lo precedieron fueron dando lugar a la formación de un Cuerpo de Topógrafos, un cuerpo técnico dedicado a la medición del terreno. En consecuencia, apareció un pequeño grupo de presión en el seno de la Administración, de profesionales que demandaban estabilidad en el trabajo al que se dedicaban, y que debido a su carácter corporativista demandaban también mayores presupuestos, mayor autonomía en su trabajo, ampliación de plantiIlas, etc. En el seno de la Administración, y como consecuencia de estos trabajos, en principio puramente científicos, fue, pues, apareciendo un grupo que también clamaba por la realización de un catastro a gran escala: un catastro sistemático, útil, completo y en el cual se trabajara de manera continua para su puesta al día. A partir de 1870, por lo tanto, apareció una presión, desde dentro y desde fuera de la Administración, a favor de levantar un catastro, algo que, sin embargo, tardó todavía más de veinticinco años en anunciarse.

La situación de crisis por la que atravesó el país a finales del siglo XIX, crisis debida a la falta de confianza en la nación, a la toma de conciencia del atraso y a la pérdida de las últimas colonias, favoreció un consenso entre los grandes partidos del turno para iniciar el levantamiento de un catastro gráfico, aunque fuera con un retraso de casi cien años con respecto al modelo que representaba Francia y con respecto, en general, a lo que estaba ocurriendo en el resto de Europa. 
Ya a finales de siglo, en 1895, se inició por primera vez el levantamiento de un catastro gráfico, que sin embargo tardó en cubrir el conjunto del país hasta la década de 1950, en razón de la agitada historia política que sufrió España en la primera mitad del siglo XX. La falta de una estabilidad política dio lugar a un proceso de avance y retroceso continuo en materia de catastro, con cambios de legislación que obligaban periódicamente a desmantelar todo lo realizado en los años anteriores. Pero la idea de levantar un catastro gráfico ya no desapareció de la Administración española desde 1895, hasta que con el "vuelo americano" de los años cincuenta se hicieron las fotografías aéreas necesarias para terminar rápidamente, en unos diez años, lo que no se había hecho en siglo y medio ${ }^{5}$.

\section{Una clase política clientelar}

La razón última por la que en España no fue posible articular sistemas fiscales y estadísticos eficaces en todo el siglo XIX está en la configuración de la sociedad española como una sociedad de patronazgo. Las relaciones de patronazgo y clientela, bien conocidas tanto entre los historiadores como entre los sociólogos y antropólogos, son relaciones sociales de intercambio entre desiguales, en virtud de las cuales una de las partes -el patrono- ofrece protección e influencia en ámbitos superiores a cambio de obtener de la otra parte -cliente- su sumisión y su apoyo leal en las contiendas políticas y sociales a las que el patrón se tenga que enfrentar. En principio, la relación clientelar es absolutamente libre y voluntaria: es una simbiosis entre dos partes que se prestan ayuda mutua en la medida de sus posibilidades; pero en realidad siempre conlleva una situación de dominación, en la que los clientes tienen pocas opciones alternativas, mientras que los patronos se sirven de la fidelidad de los clientes para asentar su poder y para reforzar la desigualdad de condiciones sociales.

Estas relaciones, conocidas desde la Antigüedad, han pervivido en diversos contextos culturales hasta nuestros días. En el mundo mediterráneo han servido frecuentemente para confeccionar facciones políticas y para hacer efectiva la extensión de los poderes centrales hacia territorios más o menos alejados. Lejos de desaparecer con la formación de los Estados liberales contemporáneos, las relaciones clientelares pervivieron como estructura interna de la vida social; y en países como España han condicionado el funcionamiento de las instituciones políticas durante el siglo XIX y buena parte del XX, determinando un tipo especial de relaciones entre el poder central y los poderes locales, al que se ha dado llamar caciquismo ${ }^{6}$.

5. La historia del catastro español contemporáneo la he desarrollado en Estado, geometría y propiedad. Los orígenes del catastro en España (1715-1941), Centro de Gestión Catastral y Cooperación Tributaria, Madrid, 1992.

6. Ernest Gellner: Patronos y clientes en las sociedades mediterráneas, Júcar, Gijón, 1986; Antonio Robles Egea (comp.): Política en penumbra. Patronazgo y clientelismo en la España contemporánea, Siglo XXI, Madrid, 1996. 
El cacique era el dominador de la sociedad local en virtud del patronazgo que ejercía sobre un número significativo de familias. Accedía al control del poder municipal -fuera por sí mismo o mediante personas de su confianza- y se erigía en representante exclusivo y permanente de la comunidad en el exterior, negociando en nombre de la comunidad con el Estado. Esta posición política del cacique venía frecuentemente a reforzar una preeminencia económica y social; y juntas, tanto la referida preeminencia socioeconómica como la posición política de intermediario, determinaban la sumisión de la vida local a sus designios, ignorando la legalidad, los derechos de los ciudadanos y el pluralismo político.

La época liberal, pues, no sólo no acabó con el funcionamiento clientelar de las relaciones sociales sino que abrió una verdadera "edad de oro" del clientelismo, que, en abierta contradicción con las leyes escritas, siguió rigiendo la estructura política y social de España a lo largo del siglo XIX. Durante las luchas políticas iniciadas en 1808 y continuadas hasta 1843 por lo menos, el aparato político y administrativo de la Monarquía tradicional se vino abajo y su lugar no fue ocupado inmediatamente por una administración de tipo moderno al servicio del estado liberal. Los esfuerzos realizados por la Corona antes de 1808 por centralizar el poder y contrarrestar la influencia nobiliaria mediante su propia red de patronazgo alternativa, se habían detenido con el debilitamiento del poder real y con la quiebra de su Hacienda, dejando a los notables locales como dueños de la situación. En consecuencia, las autoridades liberales que controlaban el poder central en Madrid no disponían de medios para extender ese poder a la totalidad del territorio nacional. Su única posibilidad para obtener recursos -información, impuestos, quintas, etc.-, así como su única posibilidad para hacer que se cumplieran las leyes y decretos del gobierno, era pactar con los poderes que de hecho controlaban el territorio: pactar con los notables locales, cuya influencia dominaba poblaciones rurales y comarcas enteras, y con las oligarquías que detentaban el poder en las ciudades. Estos notables disponían de influencia por una combinación de factores: por su acumulación de riqueza, pero también por su capital social, por las relaciones establecidas dentro y fuera de sus pueblos y por su conocimiento del funcionamiento de los mecanismos jurídicos que regían los asuntos públicos. Gracias a estos recursos ejercían una cierta protección como patronos sobre sus vecinos más modestos, a los que encuadraban siguiendo lineamientos verticales más que horizontales desde la época de lucha por la tierra que se abrió con la crisis del Antiguo Régimen. Sólo negociando con estos poderes locales, garantizando sus intereses y accediendo a sus demandas consiguieron los dirigentes liberales consolidar el trono de Isabel II, ganar la guerra civil contra los carlistas, y asentar el régimen constitucional; pues, a fin de cuentas, la movilización que se produjo en la guerra civil, tanto en el bando carlista como en el bando liberal, no fue una movilización de masas de carácter ideológico, sino que puso de manifiesto la estructura clientelar de la sociedad española, haciendo que muchas familias 
se adhirieran al bando de su patrón 7 . Incluso cabe pensar que uno de los factores decisivos en el resultado de la guerra fue la mayor eficacia del bando liberal en el ejercicio del patronazgo, gracias a la disposición sobre los recursos públicos, engrosados con la nacionalización de los bienes de la iglesia, lo que permitió reunir una red clientelar más extensa.

El "pacto" que se estableció en aquella época entre la Corona y los notables dio carta de naturaleza a los poderosos locales en el funcionamiento del nuevo Estado. Las oligarquías locales dispondrían de hecho de una gran autonomía para gobernar sus territorios como si fueran verdaderas ciudades-estado, apenas confederadas bajo el manto protector del Estado español. El gobierno central dejaría en sus manos atributos esenciales del poder, como el reparto de la carga fiscal entre los vecinos, el reclutamiento de los jóvenes que debían acudir al servicio militar o la obtención de los datos estadísticos imprescindibles para orientar la acción gubernamental. En realidad, el gobierno no tenía otro remedio que confiar estas tareas a los poderes locales, puesto que no contaba con medios propios para realizarlas por sí mismo. También dejaba en sus manos la organización de las elecciones, tolerando, de hecho, una manipulación sistemática de las consultas, lo cual permitía a las oligarquías que detentaban el poder local monopolizar la representación de sus respectivos territorios en las Cortes y en todas las instancias representativas: ayuntamientos, diputaciones provinciales, juntas consultivas, etc.

En consecuencia, en la primera mitad de los años cuarenta del siglo XIX, había tomado forma una especial configuración social y política del país, en la que un pequeño número de personajes influyentes de cada localidad se habían erigido como intermediarios entre la población y el Estado. Estos eran los caciques cuyo nombre procedía de la comparación con los jefes de las tribus indias que los españoles habían conocido en América y que habían denominado en general con esta voz que escuchó Colón en el Caribe.

A partir de 1843, terminada ya la guerra civil y convertido el partido moderado en dueño del poder por un largo tiempo, se darían condiciones de estabilidad política que permitieron gradualmente ir dotando al Estado de instrumentos con los que pudiera hacer llegar su acción a todo el territorio. Este proceso se extendió por espacio de cincuenta años, hasta finales del siglo XIX. Algunos de sus hitos fundamentales fueron la implantación de la Guardia Civil en 1844, la reforma tributaria (1845), las leyes de ayuntamientos y diputaciones (en aquel mismo año), la creación de los gobernadores civiles (1849) y la fundación de la Comisión de Estadística (1857). De esa época data también el proceso de fundación de los instrumentos técnicos que permitieran conocer el país, con el levantamiento del primer censo de población (1857) y los trabajos que se iniciaron para el

7. Sobre este tema hay una reflexión en profundidad en el artículo de Gloria Martínez Dorado y Juan Pan-Montojo: "El primer carlismo, 1833-1840", en: J. Millán (ed.): "Carlismo y contrarrevolución en la España contemporánea", Ayer, núm. 38 (2000), pp. 35-63. 
levantamiento del catastro y del mapa topográfico nacional. Ligado a esto hay que hablar también de los instrumentos que se fueron construyendo para hacer eficaz la comunicación entre el centro del Estado y la periferia: la extensión de la red ferroviaria (desde 1848) y la extensión del telégrafo (desde 1860).

Cada uno de estos hitos marcaron el inicio de un proceso, no el final. Todas estas medidas tardaron decenios en desarrollarse. Por ejemplo, la Guardia Civil se creó en 1844, pero sólo sobre el papel. Su despliegue efectivo en los medios rurales a los que iba destinada fue un proceso de más de cincuenta años, que requirió la construcción de más de dos mil cuarteles hasta finales del siglo XIX; la reforma tributaria, que se aprobó legalmente en 1845, diseñando sobre el papel un sistema de contribuciones reales similar al de Francia, necesitaba para la distribución proporcional de dichas contribuciones disponer de un catastro de la riqueza, cuyo levantamiento se inició hacia 1895-1900, pero que no se terminó hasta cincuenta o sesenta años más tarde, como hemos visto. Y así sucesivamente.

Los notables locales mantuvieron el control del territorio durante todo este proceso de construcción del Estado, de manera que estuvieron en condiciones de vetar las decisiones de las autoridades centrales. Ninguna reforma importante, ninguna ley significativa, salía adelante sin la aquiescencia de estas oligarquías. En primer lugar porque poseían una representación determinante y decisiva en las dos cámaras del Parlamento, y desde allí podían cerrar el paso a cualquier proyecto de ley. Ciertamente, los gobiernos de la segunda mitad del siglo XIX hacían poco caso de las resoluciones del Parlamento, como es bien sabido: fueron gobiernos con hábitos autoritarios y antiparlamentarios, que les llevaron a esquivar a las cámaras mediante diversos procedimientos cada vez que éstas se opusieron a los designios del ejecutivo. Pero, incluso en esos momentos en que el poder ejecutivo actuaba de forma expeditiva, sin otro apoyo que el de la Corona, sabían que era más fácil ignorar al Parlamento que a las oligarquías locales. Sabían que cualquier medida que aprobaran no tendría posibilidades de ser aplicadas en la práctica, aunque se publicara en la Gaceta de Madrid, si afectaba al poder o a los intereses de los notables locales sin ofrecerles contrapartidas. Los gobiernos que, a pesar de todo, intentaron saltarse el control de las oligarquías locales cayeron ante movimientos de apariencia revolucionaria, que más que una rebeldía popular encubrían la rebelión de los caciques.

Este fue el sentido de la revolución de 1854, cuando los notables aglutinados en las redes del moderantismo no hicieron nada por detener el pronunciamiento militar y la rebelión popular urbana contra un Gobierno que había emprendido la "aventura" autoritaria de gobernar sin su consentimiento, apoyándose exclusivamente en el poder de la Corona y de la Corte ${ }^{8}$. La interpreta-

8. Interpretación que sostuve en: "La práctica política de los gobiernos antiparlamentarios del final de la década moderada (1851-1854)", Revista de las Cortes Generales, núm. 12 (1987), pp. 7-55. 
ción de la revolución de 1868 como un conflicto entre fracciones de la elite política ${ }^{9}$ abre la puerta a una consideración de aquel conflicto en términos similares, como consecuencia del giro autoritario de los últimos gobiernos isabelinos y su consiguiente tendencia a prescindir del concurso de la mayor parte de los notables.

\section{La transformación de los notables en una elite nacional}

A pesar del poder alcanzado por los caciques desde los años treinta y cuarenta, la construcción del Estado siguió adelante e inevitablemente fue erosionando su posición política y social a medida que transcurría el siglo XIX. Cada vez que telégrafo y el ferrocarril llegaban a una localidad, la Administración central dejaba de ser allí un referente remoto y pasaba a sentirse como una realidad cotidiana en forma de documentos recibidos y expedidos, funcionarios, inspectores, etc. Cada vez que se instalaba en una comarca un puesto de la Guardia Civil, el mantenimiento del orden dejaba de ser asunto de las autoridades locales y pasaba a estar dirigido desde Madrid. Cada vez que una institución estatal abría oficinas en cualquier lugar de España, los caciques de aquel lugar perdían atribuciones, su papel de intermediarios entre la población y el Estado perdía consistencia cuando las instituciones estatales se ponían en contacto directo con los ciudadanos y la mediación del cacique parecía hacerse menos imprescindible.

Por otra parte, la materialización del Estado eninstituciones y estructuras administrativas concretas ofrecía a quienes controlaran el proceso la posibilidad de distribuir favores y beneficios materiales, que adquirían un valor especialmente atractivo en un contexto económico de atraso y de desarrollo desigual. Aquellos caciques que estuvieran dispuestos a poner su influencia al servicio del Estado y de su proyecto de construcción nacional adquirirían, a cambio, la posibilidad de distribuir entre sus clientes recomendaciones y empleos en la Administración pública, así como contratas y concesiones estatales, desgravaciones, subvenciones, información privilegiada y otros recursos de gran ayuda para los negocios. No se debe, por tanto, desdeñar la incidencia político-social de grandes empresas estatales como las aludidas: el tendido de las redes ferroviaria y telegráfica, el levantamiento del catastro y la cartografía nacional civil y militar, el censo de población y las restantes operaciones estadísticas, la inflación de las plantillas ministeriales a todos los niveles... no eran procesos políticamente neutros, sino oportunidades para comprar lealtades, que vinieron a cohesionar algunas de las redes clientelares preexistentes.

Los procesos aludidos fueron denunciados frecuentemente en la época como casos de "corrupción", al contrastar los beneficios materiales obtenidos

9. Gregorio de la Fuente Monge: Los revolucionarios de 1868. Elites y poder en la España liberal, Marcial Pons, Madrid, 2000. 
por algunos notables con los exigentes parámetros de ética pública y legalidad que el liberalismo solía proclamar en el plano doctrinal. Las acusaciones contra el marqués de Salamanca, por ejemplo, hicieron época, al politizarse en el contexto de su enfrentamiento personal con arváez y el estallido de la revolución del '54. Pero muchos otros "casos" no adquirieron la misma relevancia, porque no fueron empleados para debilitar o derribar a rivales políticos. Banqueros y contratistas vivían de los beneficios especiales de su relación con el Estado, lubricada desde su doble condición de empresarios y políticos ${ }^{10}$. Y la historiografía del siglo XX -generalmente escrita en continuidad con el discurso liberal del XIX- no ha sabido ver más allá del escándalo moral y político de este y otros casos de "corrupción".

Sin embargo, la obtención de beneficios económicos particulares ligados a conexiones y responsabilidades políticas admite otra lectura, apartada de valoraciones morales: constituye la contrapartida material del proceso de formación de los "partidos de notables" de ámbito nacional, en torno a redes clientelares preexistentes; $y$, en última instancia, revela la aparición de empresas comunes capaces de atraer a los notables hacia un proyecto nacional. El estudio de los grandes escándalos de "corrupción" del siglo XIX y las primeras décadas del XX -que no es posible abordar más que en la medida en que ha quedado reflejo en las fuentes conservadas- viene a mostrar cómo ese universo de notables locales independientes se fue articulando en partidos y grupos de interés, hasta transformarse en la clase política nacional que hizo funcionar el régimen de la Restauración"1.

De manera que, para los caciques de la segunda mitad del siglo XIX, la construcción gradual del Estado nacional español no sólo era una amenaza para su poder local tradicional, sino también una oportunidad de participar en negocios y redes de interés económico de carácter excluyente. Esta doble circunstancia creaba un marco nuevo para el ejercicio del poder. La respuesta de la mayor parte de estos caciques ante la nueva situación fue la adaptación, una adaptación a las nuevas realidades, que consistió principalmente en cambiar los términos del pacto con la clase política instalada en Madrid. Si a mediados del siglo XIX los caciques eran notables con un poder local propio, que prestaban

10. El ejemplo del político y banquero valenciano José Campo ha sido analizado en ese sentido por Justo Serna y Anaclet Pons: "La escritura y la vida. El notariado y el estudio de las redes personales burguesas en la época isabelina", en I. Burdiel (ed.): "La política en el reinado de Isabel II", Ayer, núm. 29 (1998), pp. 109-138. Para épocas posteriores, la relación entre negocios y política ha sido subrayada con mayor frecuencia; por ejemplo, por María Sierra (La familia Ybarra, empresarios y políticos, Muñoz Moya y Montraveta, Sevilla, 1992).

11. Al final de este proceso de estructuración de la clase política liberal, su aspecto era el que presentaba el Parlamento de la Restauración según el vívido retrato que hace Miguel Martorell (El santo temor al déficit. Política y Hacienda en la Restauración, Alianza Editorial, Madrid, 2000): una cámara con partidos que eran complejas redes clientelares de carácter personalista y condicionadas por la incidencia de grupos de presión ligados a intereses económicos particulares. 
su apoyo a los gobiernos a cambio de que respetaran ese poder y de que los consideraran como representantes naturales del territorio -por ejemplo en el Parlamento-, a finales de siglo los caciques se habían convertido en su mayor parte en agentes del poder central, que obedecían sumisamente los dictados del gobierno de turno a cambio de que éste les siguiera reconociendo una cierta preeminencia local y el derecho a sentarse en el Congreso o el Senado.

Aparentemente la estructura era la misma: la de un Estado formalmente unitario y centralista, que se apoyaba sobre una elite de sátrapas locales distribuidos por el territorio. En la práctica, el poder había cambiado de manos a medida que se completaba la construcción del Estado, pasando de los notables locales -a los que podemos considerar hegemónicos hacia 1850- a la clase política nacional con sede en Madrid, que era la que tenía la última palabra hacia 1900. A medida que el proceso de concentración de recursos en manos del poder central fue avanzando, los notables se mostraron menos capaces de encabezar una red clientelar independiente sobre la base de distribuir los recursos que controlaban. El futuro de estos caciques pasaba por integrarse en redes de ámbito superior, convirtiéndose en patronos intermedios para el gran dispensador de recursos que era ahora el Estado.

El proceso por el cual las redes clientelares integradas "ganaron la partida" a los notables locales independientes tuvo su punto culminante en el último cuarto del siglo XIX. Fue un proceso histórico complejo, cuya identificación se complica por el hecho de venir acompañado por una sustitución parcial de las familias implicadas en todos los niveles del poder. El periodo revolucionario de 1868-74 fue significativo a este respecto, marcando el ocaso de todo un sector de la elite isabelina, preterida en sus métodos de dominación política y social. Sus sucesores practicarían modalidades más modernas y eficaces de clientelismo, orientadas a la formación de cadenas de patronazgo más largas, capaces de vincular cada territorio con el poder central del Estado ${ }^{12}$.

Fue entonces, a partir de los años ochenta, cuando arreciaron las críticas contra "oligarquía y caciquismo", como dijera Joaquín Costa, críticas que se hicieron frecuentes en la prensa, el Parlamento, el Ateneo, los círculos intelectuales, entre los partidos liberales, republicanos, socialista... pero también entre muchos personajes que eran caciques por sus actos, aunque criticaban el fenómeno de palabra. Todo un movimiento intelectual, el regeneracionismo, lanzó su crítica al atraso político, económico, cultural y social de España basándose en el caciquismo como pieza clave que garantizaba el dominio de una oligarquía. Y cuando España perdió sus últimas colonias ultramarinas, en la guerra contra Estados Unidos, en 1898, la acusación fue unánime dentro y fuera de la clase política: la culpa de la debilidad de España la tenía el caciquismo, que era

12. Ejemplos de este cambio han sido analizados por Jesús Millán y Rafael Zurita: "Elites terratenientes y tipos de caciquismo. La casa de Rafal/Vía Manuel entre la revolución liberal y la crisis de la Restauración", Historia Agraria, núm. 16 (1998), pp. 153-181. 
a la vez causa y reflejo del atraso y de la postración nacional. No obstante, ese fenómeno político y social existía desde mucho tiempo antes, sin que las críticas hubieran alcanzado este nivel de consenso.

La crítica frontal al caciquismo apareció en el momento en que éste cambió de significado: si a lo largo del siglo XIX había servido para sustentar el proceso de construcción del Estado, integrando paulatinamente a los notables en redes nacionales, a partir del cambio de siglo se presentaría como un elemento arcaico que frenaba las posibilidades de una verdadera construcción nacional. Los avances de la industrialización y del capitalismo en España habían llevado a un contexto de conflictividad social creciente y el nacionalismo se presentaba como la alternativa capaz de recuperar la cohesión, encontrar vínculos emocionales interclasistas y frenar la posibilidad de una confrontación social, de una guerra de clases. El caciquismo fue criticado por los nacionalistas de todo tipo en torno al cambio de siglo como una lacra de la sociedad española, que se manifestaba en la corrupción e ineficacia de las instituciones del Estado. Pero era mucho más que eso, era la manifestación específicamente española del fenómeno del patronazgo, que suministraba la estructura social básica del país. Fue un sistema de dominación social adaptado a una época de transición, cuya vigencia coincide con el período de desmantelamiento del Antiguo Régimen y de construcción del Estado nacional.

El mayor éxito del caciquismo consistió en que durante mucho tiempo no se hablara de él, lo que indica que existía un consenso tácito en torno a su legitimidad. Incluso los grupos dominados por este sistema y los grupos a los que el sistema excluía de toda participación en el poder se abstuvieron de condenarlo y de formular alternativas hasta el último cuarto del siglo XIX. Los caciques consiguieron dominar los resortes fundamentales de la vida local e incluso del poder estatal durante mucho tiempo, al menos durante el período que va de 1833 a 1898, y probablemente durante mucho más, quizá desde 1808 hasta 1923, o hasta 1931. Y lograron que los pueblos a los que dominaban aceptaran esta situación, pues no se conocen rebeliones contra caciques durante toda esta época de intensa movilización social y de frecuentes disturbios por cuestiones políticas y económicas. No es que el caciquismo no fuera conflictivo, que sí lo era (y a veces recurría incluso al empleo de la violencia); pero esa conflictividad y violencia eran más bien fruto del enfrentamiento entre redes clientelares rivales que empleaban cuadrillas de bandoleros o de matones para ocuparse del trabajo sucio, castigando por la fuerza a quienes se oponían a su poder. Resulta mucho más dudoso el que puedan interpretarse ciertas revueltas campesinas antioligárquicas o el propio auge del bandolerismo como ejemplos de una violencia anticaciquil que viniera a poner en cuestión el modelo de relación clientelar y las privaciones que imponía. La dominación social implícita en el caciquismo se imponía cotidianamente sin recurrir a la fuerza; su fuerza estaba en la costumbre de obedecer y seguir a determinadas familias en virtud de su posición y esperando a cambio favores concretos de todo tipo. Estas familias 
gozaban así de una hegemonía cultural que les permitía dominar los recursos locales, la mediación con poderes supuestamente superiores e incluso las mentalidades colectivas.

La existencia de relaciones de patronazgo no era nueva en el siglo XIX pues se había constituido en la forma normal de establecer vínculos de cooperación entre desiguales desde siglos atrás. Lo que era nuevo era su pervivencia en la clandestinidad, al margen y en contradicción con la estructura oficial de la sociedad y del Estado que pretendía darle forma. Era nuevo el empleo de las relaciones clientelares para obtener ventajas particulares e ilegales en un medio definido por la libre competencia, la igualdad legal de los ciudadanos, y el principio del mérito para el acceso a los empleos públicos. No era nuevo que los poderosos monopolizasen la administración de justicia en su favor, pero sí lo era que las redes caciquiles permitieran manipular a jueces y tribunales después de que hubiesen sido abolidos los señoríos y las jurisdicciones privilegiadas, proclamando que todos los ciudadanos eran iguales ante la ley y disponían de idénticas garantías procesales.

\section{El poder del cacique}

La esencia del poder de los caciques era su capacidad de mediación: eran intermediarios entre el pueblo llano y los medios oficiales. Su situación estratégica era más favorable en el medio rural, en donde actuaban como únicos intermediarios entre los pueblos y el mundo exterior; su poder, pues, era mayor cuanto más aislados estuvieran los pueblos ${ }^{13}$. Los notables locales propiamente dichos, aquellos caciques que conseguían escaños de diputados por su propia influencia local y no por la intervención del gobierno central, eran más fuertes en las regiones de España en las que el relieve y el poblamiento disperso imponían mayores dificultades para las comunicaciones, zonas como Galicia o Asturias, mientras que la capacidad del poder central para influir sobre los resultados electorales de Castilla la Nueva, Andalucía, Murcia o Valencia demuestra que el peso del Estado ya se había hecho sentir en estas regiones más accesibles y mejor comunicadas. Los caciques de esta mitad sur no eran ya sino agentes de los grandes partidos dinásticos que se turnaban en el gobierno central.

13. Esta relación del aislamiento rural con el poder caciquil queda de manifiesto en la historiografía sobre el caciquismo gallego, en trabajos como los de J.A. Durán (Historia de caciques, bandos e ideologías en la Galicia no urbana: Rianxo, 1910-1914, Siglo XXI, Madrid, 1972), Francisco Candeira Mosquera (Caciquismo e poder local na Galicia da Restauracionm: Distrito de Ponteareas, 1881-1894, Galicia-Sur, Puentearéas, 1990), José María Cardesín (Tierra, trabajo y reproducción social en una aldea gallega, s. XVIII-XX: muerte de unos, vida de otros, Ministerio de Agricultura, Pesca y alimentación, Madrid, 1992) y Xosé Ramon Veiga Alonso (O conde de Pallares e o seu tempo, 1828-1908. Aproximación ó activismo das elites na Galicia decimonónica, Diputación Provincial, Lugo, 1999.) 
La mediación del cacique ante el Estado se hacía para lograr dos tipos de favores, como ha venido destacando la historiografía. Por un lado, el cacique era el protector del pueblo en sus relaciones con el Estado y debía obtener favores colectivos, como el paso de carreteras o vías ferroviarias, la dotación de servicios públicos como un juzgado o un puesto de la Guardia Civil, o la rebaja del cupo tributario atribuido a la localidad en los repartos del Ministerio de Hacienda. En este mismo papel de defensor de intereses colectivos, todo cacique que se preciara debía ser capaz de encabezar grupos de presión para defender los intereses de un sector de la actividad económica fuertemente implantado en su cacicazgo. Como tal debía movilizarse cuando proyectos legislativos o gubernamentales amenazaban con perjudicar esos intereses agrícolas, industriales, comerciales o mineros, de los que dependían los ingresos de gran parte de sus vecinos, y frecuentemente los suyos propios ${ }^{14}$.

Además de esta labor de protector de la comunidad -de representante en el sentido más estricto de la palabra-, el cacique era también un patrón con obligaciones especiales hacia los que formaban parte de su clientela, hacia determinados miembros de la comunidad. A estos clientes suyos el patrono tenía que entregarles otro tipo de favores, no colectivos sino personalizados, que habitualmente solían ir en detrimento de otras personas que no gozaban de esa protección específica. El discurso público de los caciques y de sus clientes sólo hacía referencia al primer tipo de favores. La propaganda presentaba al cacique como el protector del pueblo en su conjunto, lo que aumentaba el prestigio del cacique dentro de su comunidad y legitimaba su continuidad como representante. Esta propaganda plasmaba la imagen de su protector inaugurando monumentos en su honor, poniendo su nombre en las calles y plazas de los pueblos que controlaba su red clientelar, nombrándole hijo predilecto del pueblo y haciendo discursos en los que se agradecían al cacique sus desvelos por el bienestar del pueblo con motivo de la inauguración de una carretera, estación de ferrocarril, escuela, juzgado, etc. ${ }^{15}$

En lo fiscal esto significaba que los caciques se presentaban a sí mismos como negociadores colectivos frente a un fisco voraz, en defensa de los intereses del pueblo en su conjunto. Eran ellos los que intentaban obtener la presión fiscal más baja posible para el pueblo como colectivo. Así pues, y según la propaganda caciquil, a todos los miembros de la comunidad les interesaba por igual la posibilidad de ocultar riquezas a Hacienda, puesto que todos se bene-

14. Esta labor del cacique como agente de intereses económicos y grupos de presión ha sido resaltada, en relación con los problemas de la Hacienda Pública, por el libro de Miguel Martorell: El santo temor al déficit..., op. cit.

15. Un análisis de este aspecto "benéfico" de la acción caciquil, en: Manuel Marín: "El cacique protector", Historia Social, núm. 36 (2000), pp. 21-34. El autor ha desarrollado la idea de una economía moral del caciquismo en su trabajo inédito: Un cacique catalan. Clientélisme et domination politique en Espagne (1876-1887). 
ficiaban de la ocultación frente a un poder que se consideraba ajeno: el poder del Estado, del fisco, frente al cual todos debían estar unidos.

Junto a ese discurso público, al que nadie osó restar legitimidad, había un discurso privado, que se descubre en la correspondencia de los caciques. En esa correspondencia era donde los clientes pedían favores individuales a su patrono e incluso a veces obtenían una respuesta escrita junto a la concesión -o denegación- del favor. El tipo de favores que se pedían a los caciques son bien conocidos, pues habitualmente eran los mismos: un trato de favor en el reparto de los impuestos, la exención del servicio militar de un hijo, la aceleración de un pleito en los tribunales, una sentencia favorable o la obtención de un puesto de trabajo. Muchos de los favores que intercambiaban los patronos con sus clientes en este sistema eran favores inmateriales, o difíciles de contabilizar de manera cuantitativa: votos, sumisión, reconocimiento... por un lado; y a cambio de eso: resoluciones judiciales o administrativas, algún cargo, protección, favoritismo en la aplicación de la ley.

El intercambio de favores entre el cacique y sus clientes no podía ajustarse a los criterios mercantiles de la economía capitalista en expansión; al contrario, hacía que la vida social se rigiera por principios ajenos al espíritu del capitalismo y contradictorios con su esencia. Tales criterios eran los de la reciprocidad, es decir, un intercambio aparentemente gratuito de bienes y servicios que se sustentaban en la existencia de una relación social y no meramente económica entre los partícipes. Quien prestaba un favor al otro, fuera cacique o cliente, no esperaba su pago inmediato en otro favor de valor equivalente, porque sería imposible establecer la equivalencia y porque tal vez la ocasión propicia para recibir otro favor a cambio no se presentara hasta mucho tiempo después, cuando las circunstancias lo hicieran posible y necesario. Quien prestaba favores a su patrono o cliente estaba alimentando y fortaleciendo un vínculo social, un vínculo con la otra parte, de la cual se esperaría un trato recíproco cuando tuviera necesidad y se lo pidiera.

\section{Conclusión}

Precisamente los terrenos de la estadística y de la Hacienda, que hemos elegido para desarrollar nuestro argumento, resultan los más reveladores de la situación descrita. Las oligarquías locales que dirigieron y condicionaron la construcción del Estado español a lo largo del siglo XIX se esforzaron por defender su poder de hecho y sus intereses materiales, y eso incluía defender dos recursos especialmente valiosos que controlaban, dos recursos que la modernización efectiva del Estado podía arrebatarles:

A) Por un lado, el control de la información: los notables locales basaron gran parte de su poder como mediadores en el monopolio de la información acerca del territorio, la población y los recursos económicos de 
sus respectivas localidades. La Administración de la primera mitad del XIX no podía obtener por sus propios medios ningún dato sobre el país, de manera que necesitaba la intermediación de los poderes locales para realizar censos, estadísticas y repartos de tributos. Con ese poder de mediadores en el suministro de datos, los notables locales podían graduar la presión del poder central y boicotear las líneas de gobierno que no fueran de su agrado. A medida que esa situación fue cambiando en la Restauración, por el desarrollo de instituciones propias encargadas de levantar el censo, el mapa topográfico nacional, el catastro y las estadísticas administrativas y económicas, el poder de los caciques locales estaba sentenciado, pues ya no podrían utilizar el control de la información como elemento de presión y de negociación.

B) Por otro lado, la inmunidad fiscal de hecho: el sistema de los amillaramientos significaba en la práctica la entrega a las oligarquías locales de un poder muy amplio en la distribución de la carga fiscal, poder que empleaban en beneficio propio y de sus redes clientelares. La ocultación fiscal de la riqueza era practicada sistemáticamente y en proporciones tan grandes que no podían ser ignoradas por la Administración central. Esa ocultación era tolerada desde el gobierno porque era el precio del control del territorio que los notables locales aseguraban mediante su relación con redes clientelares de alcance nacional. Ese fraude fiscal masivo y tolerado no empezó a remitir hasta que, con el cambio de siglo, se inició el levantamiento de un catastro fiable en la mitad sur de la península, e iría desapareciendo lentamente a medida que el levantamiento catastral se fue completando, en un complicado proceso que no terminó hasta los años cincuenta del siglo XX.

El reparto de las contribuciones directas nos ofrece un ejemplo de singular importancia de la actitud de subordinación pasiva y resignación al poder de los patronos que predominó entre la población rural española a lo largo del siglo XIX. Según el sistema que hemos descrito, la Hacienda del XIX recaudaba sus contribuciones distribuyendo a cada localidad un cupo fijo que sus autoridades se encargarían de repartir entre sus vecinos, asignando la carga fiscal con amplias dosis de arbitrariedad y de favoritismo. Evidentemente, las juntas locales que repartían cupos tributarios entre los vecinos actuaban según la lógica del caciquismo, permitiendo en mayor medida la evasión fiscal de los familiares y clientes. Como tenía que recaudarse el cupo íntegro para entregárselo a la Administración provincial de Hacienda, al favorecer a unos vecinos en el reparto se perjudicaba correlativamente a otros, a los que se exigía un esfuerzo fiscal suplementario. Las leyes ofrecían a quienes se creyeran perjudicados canales para reclamar, solicitando de la Administración una investigación objetiva de la riqueza que permitiera repartir la contribución en proporción a la riqueza efectiva de cada contribuyente. Sin embargo, y aunque abundan las pruebas de los 
abusos e irregularidades que se cometían en los repartos municipales, en general los vecinos no reclamaban, los agravios eran asumidos y la injusticia silenciada. Esta complicidad con el cacique, sostenida en detrimento de los intereses económicos inmediatos -es decir, que el contribuyente aceptara pagar más impuestos de los que le correspondía con tal de no enfrentarse con la oligarquía municipal-, este sacrificio era un servicio que debía de tener su contrapartida. $\mathrm{Si}$ el cacique no compensaba estas acciones - $\mathrm{u}$ omisiones- con favores individuales y colectivos a sus vecinos, éstos dejarían de encontrar interesante el mantenimiento del orden establecido y quizás se plantearían la posibilidad de apelar contra el reparto municipal de las contribuciones; algo que se hizo, como ya se ha dicho, en muy contadas ocasiones. Semejante decisión, la de apelar a una instancia superior para dirimir el reparto de la carga fiscal en la localidad, era una grave amenaza que pendía sobre la cabeza de los notables locales, pues suponía la posibilidad de una connivencia entre las clases populares y la Administración central del Estado, a la que podían Ilamar en su ayuda; y semejante intervención acabaría con el espléndido aislamiento de la localidad, dislocaría el orden tradicional, privaría tal vez al cacique de su poder como único intermediario entre el pueblo y el Estado.

El ejemplo de la fiscalidad, muestra que, incluso antes de la extensión del sufragio universal, los clientes de la más baja extracción social podían hacer la vida de los caciques fácil o difícil; tenían algo que dar a cambio de los favores que pedían al cacique. Los ejemplos podrían multiplicarse, pues la existencia de una legislación más o menos irreal que reconocía a los ciudadanos la capacidad para acudir a los tribunales o para reclamar a la Administración cada vez que vieran vulnerados sus derechos, otorgaba a cada individuo un arma, aunque sólo fuera potencial, contra quienes aplicaban las leyes en su provecho exclusivo y hacían caso omiso de cualquier principio de equidad. Esa posibilidad de recurrir abría un cambio para el intercambio, sin el cual no podría hablarse de relación caciquil.

La generalización del derecho de voto a todos los varones adultos en 1890 no significó un salto cualitativo, pues fue un activo más que los clientes podrían ofrecer a sus patronos para mejorar la reciprocidad del vínculo con ellos y eventualmente reforzar su poder negociador. Algunos estudios consideran que el voto más que un derecho político fue para los electores con menos conciencia política una oportunidad de hacer patente su agradecimiento al patrono del que dependían para obtener todo tipo de favores, incluido quizá el sustento diario. La ampliación del derecho de voto atribuyó a las masas populares un poder efectivo, pero fue un poder que aquellas no emplearon directamente para cambiar la composición del Parlamento. Las mayorías continuaron repartiéndoselas los dos partidos tradicionales conservadores y liberales como si nada hubiera cambiado. Las masas campesinas emplearon el poder político que les daba la ampliación del sufragio para obtener beneficios particulares inmediatos, transformando la deferencia hacia sus antiguos amos en un intercambio de favores 
sobre una base de negociación. En ese intercambio el voto era una moneda de cambio más, era una moneda que podía incluso sustituir al fraude fiscal. Los caciques que pedían el voto encontraron crecientes dificultades para pedir también el silencio cómplice con la ocultación de sus propiedades o con el reparto desigual de la carga tributaria, en una época además en la que la Administración del Estado estaba empezando a regular esa carga mediante datos propios, funcionarios y técnicos independientes. En la década de los noventa, todo el entramado tradicional del clientelismo rural entraba en crisis y se veía obligado a adaptarse a las nuevas condiciones que imponía la existencia efectiva de un estado que se empezaba a hacer notar en todo el territorio. 